\title{
A close neuroanatomical relationship between the enkephalinergic (methionine-enkephalin) and tachykininergic (substance $P$ ) systems in the alpaca diencephalon
}

\author{
Pablo Sánchez ${ }^{1}$, Manuel Lisardo Sánchez ${ }^{*}$, Arturo Mangas ${ }^{1,2}$, \\ Luís Ángel Aguilar ${ }^{3}$, Rafael Coveñas $^{1}$
}

${ }^{1}$ Institute of Neuroscience of Castilla y León (INCYL), Laboratory of Neuroanatomy of the Peptidergic Systems (Lab. 14), University of Salamanca, Salamanca, Spain

${ }^{2}$ PolyNeuroS, Villenave d'Ornon, France

${ }^{3}$ San Ignacio de Loyola University (USIL), Faculty of Health Sciences, Lima, Peru

\begin{abstract}
Introduction. In the alpaca diencephalon, the distribution of immunoreactive cell bodies and fibers containing methionine-enkephalin (MET) or substance P (SP) has been studied.

Material and methods. The immunohistochemical study was performed by standard method on the diencephalon of four male alpacas that lived at sea level.

Results. Nerve fibers containing MET or SP were widely distributed in the thalamus and hypothalamus. METand SP-immunoreactive fibers showed a similar distribution in the whole diencephalon. Immunoreactive cell bodies containing MET or SP were only observed in the hypothalamus. The distribution of MET-immunoreactive cell bodies was more widespread than that observed for cell bodies containing SP.

Conclusions. A close neuroanatomical relationship between the tachykininergic (SP) and enkephalinergic (MET) systems was observed in the whole diencephalon suggestive of the existence of multiple physiological interactions between both systems. (Folia Histochemica et Cytobiologica 2020, Vol. 58, No. 2, 135-146)
\end{abstract}

Key words: Lama pacos; hypothalamus; thalamus; methionine-enkephalin; substance P; IHC

\section{Introduction}

The ungulate alpaca (Lama pacos) (family: Camelidae; order: Artiodactyla) can live from $5,000 \mathrm{~m}$ altitude to the sea level and this means that these animals have unique special physiological adjustment mechanisms in which neuroactive substances could

Correspondence address: Dr. Manuel Lisardo Sánchez Universidad de Salamanca

Instituto de Neurociencias de Castilla y León (INCYL)

Laboratorio de Neuroanatomía de los Sistema

Peptidérgicos (Lab. 14)

c/ Pintor Fernando Gallego, 1

37007-Salamanca, Spain

phone: +34 923294400 ext. 1856

fax: +34 923294549

e-mail: lisardosanchez8@gmail.com be involved [1]. The diencephalon plays important physiological functions: the thalamus, among other functions, is closely related to the relay of sensory information and regulation of sleep and wakefulness, whereas the hypothalamus plays a crucial role as a neuroendocrine center. Substance P (SP) (an undecapeptide member of the tachykinin family of peptides) and methionine-enkephalin (MET) (a pentapeptide that belongs to the opioid family of peptides) (Fig. 1) are widely distributed throughout the mammalian central nervous system (CNS). It is known that SP and MET are involved in functional and pathophysiological activities (e.g., inflammation, feeding behavior, immune response, neuroendocrine and visual mechanisms, learning, cancer, pain, depression, stress) [2-9]. These actions are mediated by neurokinin and opiate receptors which are transmem- 


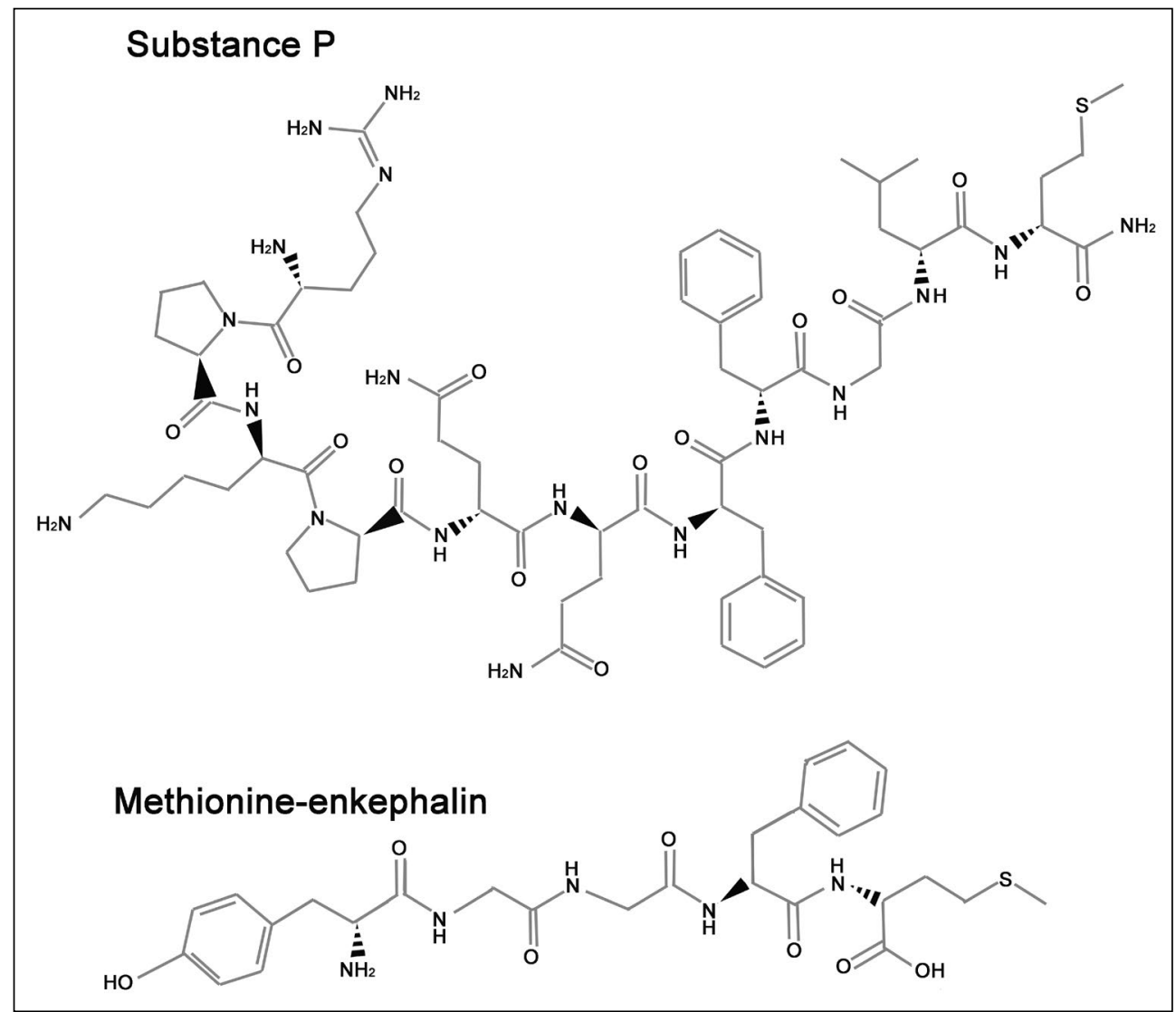

Figure 1. Chemical structures of substance $P$ and methionine-enkephalin.

brane G-protein coupled receptors. The neurokinin-1 receptor shows a preferential affinity for SP, whereas MET is a potent agonist of the delta opioid receptor and to a lesser extend of the mu receptor [2].

Our group has previously studied the distribution of several neuropeptides in the alpaca diencephalon (somatostatin-28) (1-12), calcitonin gene-related peptide (CGRP), adrenocorticotropic hormone (18-39), ACTH, alpha-melanocyte-stimulating hormone (alpha MSH), beta-endorphin (1-27), alpha-neo-endorphin, leucine-enkephalin, and neurotensin) [10-14]. In this study we aimed to describe for the first time, the distribution of immunoreactive cell bodies and fibers containing MET or SP in the alpaca diencephalon since in other mammals (e.g., rat, cat, monkey) a neuroanatomical relationship between SP and MET in the CNS has been previously reported [15-20].

\section{Material and methods}

Animals and tissue preparation. As previously reported [14], the study was carried out according to Spanish and Peruvian laws and under the supervision of the Research Commission of the Cayetano Heredia Peruvian University (Lima, Peru).
Four male adult alpacas (70-80 kg) were always kept at sea level and were obtained from the Cayetano Heredia Peruvian University (Faculty of Veterinary Medicine and Animal Sciences) [14]. As previously described [14], alpacas were deeply anaesthetized (ketamine $(10 \mathrm{mg} / \mathrm{kg})$ and xylazine $(4 \mathrm{mg} / \mathrm{kg})$, i.v. $)$, heparinized and perfused via the carotid artery with cold $\mathrm{NaCl}(0.9 \%)$ and followed by perfusion with cold paraformaldehyde (4\% in $0.15 \mathrm{M}$ phosphate-buffered saline (PBS), pH 7.2). Diencephalons were dissected out, post-fixed overnight in paraformaldehyde and cryoprotected by immersion in increasing (10-30\%) concentrations of sucrose solution until they sank. Using a cryostat, serial frontal sections (50 $\mu \mathrm{m}$ thick) were obtained. Two of five sections were used for immunohistochemistry: section 1 , for anti-SP staining; section 2, for histological control or to be stained with cresyl violet to delineate/identify the diencephalic nuclei; section 3, for anti-MET staining; sections $4-5$ were kept for other experimental purposes. The distance between sections 1 and 6 (and so on, kept in the same container) was about $200 \mu \mathrm{m}$. Thus, sections kept in slide container 1 were used for anti-SP and those kept in container 3 for anti-MET. In each container, 25-30 frontal sections/animal were collected. Sections were kept in PBS at $4^{\circ} \mathrm{C}$ for $2-6$ days. 
Immunohistochemistry and specificity of the antisera. Free-floating immunohistochemistry was performed as previously reported $[14,21]$. Sections were washed in PBS and incubated in PBS containing Triton X-100 (0.3\%, Panreac, Barcelona, Spain) and normal horse serum (1\%, Sigma-Aldrich, Madrid, Spain) for $30 \mathrm{~min}$. Then, sections were incubated overnight $\left(4^{\circ} \mathrm{C}\right)$ in the latter PBS solution containing anti-Met-5 antiserum $(1 / 3,000)$ or anti-SP antiserum $(1 / 3,000)$. Later, sections were washed in PBS and incubated in biotinylated anti-rabbit IgG (1:200) (Vector Laboratories, Burlingame, CA, USA) for $1 \mathrm{~h}$. Then, sections were rinsed with PBS and treated with Vectastain ABC reagent (1:100) (Vector Laboratories) for $1 \mathrm{~h}$. Sections were washed in PBS (30 min) and Tris-HCL buffer (10 min) (Panreac). Using 3, 3'-diaminobenzidine (Sigma-Aldrich) as chromogen and $\mathrm{H}_{2} \mathrm{O}_{2}$ the tissue bound peroxidase was developed. Finally, sections were washed with PBS and coverslipped with glycerol/PBS (1:1).

As formerly reported [22-24], the polyclonal primary antibodies (anti-SP; anti-MET) used in this study were raised in rabbits against immunogens assembled by coupling the full synthetic MET or SP to a carrier protein (human serum albumin) with glutaraldehyde. Both antibodies were obtained at the laboratory of Professor Gérard Tramu (University of Bordeaux I, Talence, France). Moreover, the immunological properties of the anti-MET and anti-SP antisera have been previously published [22-24]. To confirm the specificity of both antisera, histological controls were carried out: 1) in the first incubation bath, the first antiserum was omitted; 2) the primary antiserum was preabsorbed with an excess of the antigen $(100 \mu \mathrm{g} / \mathrm{mL}$ of diluted antiserum; e.g. anti-SP with $\mathrm{SP})$; and 3) the primary antiserum was preabsorbed with an excess $\left(10^{-7} \mathrm{M}\right)$ of heterologous antigens (e.g. anti-MET with leucine-enkephalin). In all cases, the results confirmed the specificity of the immunoreactivity observed in the alpaca diencephalon. Moreover, as previously reported [14] and to avoid interference by endogenous peroxidase, sections were treated with $\mathrm{H}_{2} \mathrm{O}, \mathrm{NaOH}$ and $\mathrm{NH}_{3}$ (Panreac) before the immunohistochemical technique was performed.

Mapping. Mapping was carried out according to the frontal planes of the alpaca diencephalon (the brain atlas used in this study is available from the Mammalian Brain Collections of the University of Wisconsin, Madison, WI, U.S.A.) and according to the alpaca diencephalic frontal sections published in previous papers [10-14]. For nomenclature of the diencephalic nuclei, we followed the nomenclature used in previously published works carried out in the alpaca [10-14]. Using an Olympus DP-50 digital camera (Olympus, Tokyo, Japan) attached to a Kyowa Unilux 12 microscope (Kyowa, Tokyo, Japan), photomicrographs were taken and Adobe Photoshop CS6 software was used to adjust brightness and contrast.

As previously published [10-14], the density of the immunoreactive fibers was considered as high, moderate, low and single. Sections were viewed at constant magnification with reference to photographs in which high, moderate or low densities had been previously determined [10-14]. The density of the immunoreactive cell bodies was considered as high ( $>20$ perikarya/section), moderate (10-20 perikarya/ /section) and low ( $<10$ perikarya/section). Moreover, cell bodies were classified into three categories: large $(>25 \mu \mathrm{m}$ diameter), medium sized $(15-25 \mu \mathrm{m})$ and small $(<15 \mu \mathrm{m})$ [14]. The size was measured using a micrometer grid with the nucleus in the focal plane.

\section{Results}

\section{General considerations}

Figures 2-5 show the density and distribution of the immunoreactive structures (cell bodies and fibers) for MET/SP found in the alpaca diencephalon. In this region, 40/42 tracts/nuclei $(95 \%)$ contained SP-immunoreactive (-Ir) cell bodies and/or fibers, whereas the same percentage was observed for METIr structures. In all thalamic tracts/nuclei (25 in total), SP- and MET-Ir structures were observed (100\%), whereas in $15 / 17$ (88\%) of nuclei of the hypothalamus immunoreactivity for both neuropeptides was found.

SP- and MET-Ir fibers showed a widespread distribution in the alpaca diencephalon. Except for the optic tract and optic chiasm, in the diencephalon SP and MET immunoreactive fibers were observed in almost all diencephalic tracts/nuclei $(40 / 42,95 \%)$ and hence the distribution of both immunoreactive fibers was similar (Fig. 2; Table 1). In addition, in the alpaca diencephalon the density of both immunoreactive fibers was similar (Fig. 2; Table 1).

In the diencephalon, no SP- or MET-immunoreactive cell body was observed in the thalamus, whereas in the hypothalamus cell bodies containing SP were only visualized in one nucleus $(6 \%)$ and those containing MET in six hypothalamic nuclei (35\%). Thus, in the alpaca hypothalamus the distribution and number of cell bodies containing MET was higher than those containing SP. The morphological characteristics of the SP- and MET-immunoreactive cell bodies are shown in Table 2.

Finally, it is important to remark that in different regions of the same diencephalic nucleus, high and moderate densities of the studied structures were observed (Table 1). In these cases, to obtain the percentages appearing below the highest density was chosen.

\section{Thalamus}

No cell body containing SP or MET was found, but all thalamic tracts/nuclei (25 in total) showed SP- and MET-Ir nerve fibers (Fig. 2; Table 1). Thus, a similar distribution for SP- and MET-immunoreactive 


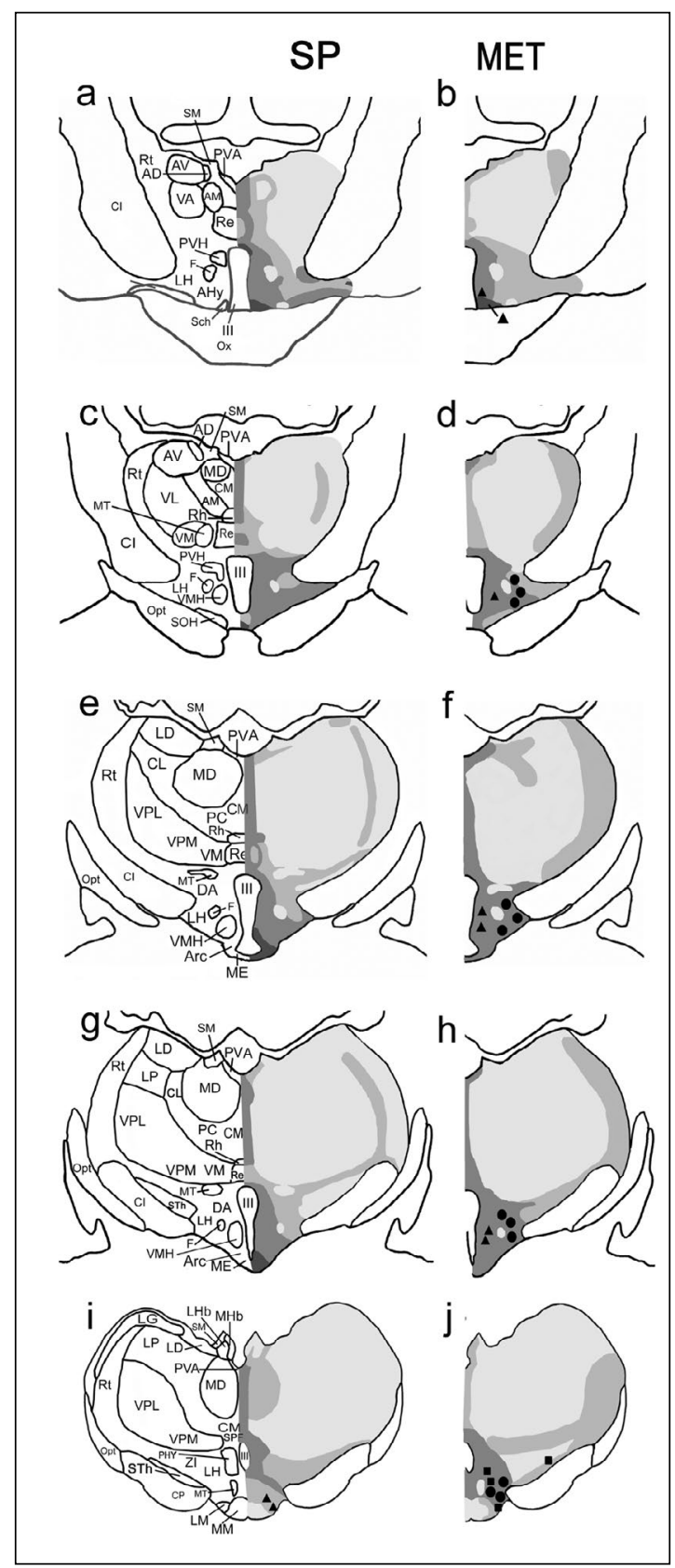

Figure 2. Distribution of substance P- (SP) and methionine-enkephalin (MET)-immunoreactive fibers and cell bodies in frontal planes of the alpaca diencephalon ( $\mathbf{a}-\mathbf{j})$ from rostral (a) to caudal (j) levels. Cell bodies containing the peptides are represented by closed circles (high density), triangles (moderate density) and squares (low density), whereas immunoreactive fibers are represented by slightly dark (single axons), moderately dark (low density), strongly dark (moderate density), and dark (high density). Abbreviations: III — third ventricle; AD — anterodorsal thalamic nucleus; AHy — anterior hypothalamic area; AM — anteromedial thalamic nucleus; Arc — arcuate nucleus; AV — anteroventral thalamic nucleus; CI — capsula interna; $\mathrm{CL}$ - centrolateral thalamic nucleus; $\mathrm{CM}$ - central medial thalamic nucleus; $\mathrm{CP}$ - cerebral peduncle; DA — dorsal hypothalamic area; F - fornix; IP — interpeduncular nucleus; LD - laterodorsal thalamic nucleus; LG - lateral geniculate nucleus; LH — lateral hypothalamic nucleus; LHb — lateral habenular nucleus; LM — lateral mammillary nucleus; LP — lateroposterior thalamic nucleus; MD — mediodorsal thalamic nucleus; ME — median eminence; MHb - medial habenular nucleus; MM - medial mammillary nucleus; MT - mammillothalamic tract; Opt — optic tract; Ox — optic chiasm; PC - paracentral thalamic nucleus; PHy - posterior hypothalamic nucleus; PVA — paraventricular thalamic nucleus; PVH — paraventricular hypothalamic nucleus; Re — reuniens thalamic nucleus; Rh — rhomboid thalamic nucleus; $\mathrm{Rt}$ - reticular thalamic nucleus; Sch — suprachiasmatic nucleus; SM — stria medullaris; SOH — supraoptic hypothalamic nucleus; SPF — subparafascicular thalamic nucleus; STh — subthalamic nucleus; VA — ventroanterior thalamic nucleus; VL — ventrolateral thalamic nucleus; VM — ventromedial thalamic nucleus; VMH — ventromedial hypothalamic nucleus; VPL — ventroposterior thalamic nucleus, lateral part; VPM — ventroposterior thalamic nucleus, medial part; ZI — zona incerta. 
Table 1. Alpaca diencephalon: distribution and density of SP- and MET-immunoreactive cell bodies and fibers

\begin{tabular}{|c|c|c|c|c|}
\hline \multicolumn{5}{|c|}{ Thalamus } \\
\hline & \multicolumn{2}{|c|}{ SP } & \multicolumn{2}{|c|}{ MET } \\
\hline Nucleus & CB & Fibers & CB & Fibers \\
\hline $\mathrm{AD}$ & - & $\mathrm{s} /+$ & - & $\mathrm{s}$ \\
\hline $\mathrm{AM}$ & - & $\mathrm{s} /+$ & - & $\mathrm{s}$ \\
\hline $\mathrm{AV}$ & - & $\mathrm{s} /+$ & - & $\mathrm{s}$ \\
\hline $\mathrm{CL}$ & - & $\mathrm{s}$ & - & $\mathrm{s}$ \\
\hline $\mathrm{CM}$ & - & ++ & - & $\mathrm{s} /++$ \\
\hline $\mathrm{CP}$ & - & $\mathrm{s} /+$ & - & $\mathrm{s}$ \\
\hline LD & - & $\mathrm{s}$ & - & $\mathrm{s} /+$ \\
\hline LG & - & $\mathrm{s}$ & - & $\mathrm{s}$ \\
\hline $\mathrm{LHb}$ & - & $\mathrm{s} /+$ & - & $\mathrm{s}$ \\
\hline LP & - & $\mathrm{s}$ & - & $\mathrm{s}$ \\
\hline MD & - & $\mathrm{s} /+$ & - & $\mathrm{s} /+$ \\
\hline $\mathrm{MHb}$ & - & $\mathrm{s} /+$ & - & + \\
\hline PC & - & $\mathrm{s}$ & - & $\mathrm{s}$ \\
\hline PVA & - & $+/++$ & - & ++ \\
\hline $\mathrm{Re}$ & - & $+/++$ & - & $\mathrm{s} /++$ \\
\hline $\mathrm{Rh}$ & - & $+/++$ & - & $\mathrm{s} /++$ \\
\hline $\mathrm{Rt}$ & - & $\mathrm{s} /+$ & - & $\mathrm{s} /+$ \\
\hline SM & - & $\mathrm{s}$ & - & $\mathrm{s} /+$ \\
\hline SPF & - & ++ & - & ++ \\
\hline STh & - & + & - & + \\
\hline VA & - & $\mathrm{s}$ & - & $\mathrm{s}$ \\
\hline $\mathrm{VL}$ & - & $\mathrm{s}$ & - & $\mathrm{s}$ \\
\hline $\mathrm{VM}$ & - & $\mathrm{s} /+$ & - & $\mathrm{s}$ \\
\hline VPL & - & $\mathrm{s}$ & - & $\mathrm{s}$ \\
\hline VPM & - & $\mathrm{s}$ & - & $\mathrm{s}$ \\
\hline \multicolumn{5}{|c|}{ Hypothalamus } \\
\hline & \multicolumn{2}{|c|}{ SP } & \multicolumn{2}{|c|}{ MET } \\
\hline Nucleus & CB & Fibers & CB & Fibers \\
\hline AHy & - & $++/+++$ & + & $+/+++$ \\
\hline Arc & - & +++ & - & ++ \\
\hline DA & - & ++ & - & $+/++$ \\
\hline $\mathrm{F}$ & - & $\mathrm{s} /+$ & - & $\mathrm{s}$ \\
\hline LH & - & $+/++$ & +++ & ++ \\
\hline $\mathrm{LM}$ & + & $+/++$ & ++ & ++ \\
\hline $\mathrm{ME}$ & - & +++ & - & ++ \\
\hline MM & - & $\mathrm{s} /+$ & - & $\mathrm{s} /+$ \\
\hline MT & - & $\mathrm{s} /+$ & - & $\mathrm{s}$ \\
\hline Opt & - & - & - & - \\
\hline $\mathrm{Ox}$ & - & - & - & - \\
\hline PHy & - & $++/+++$ & ++ & ++ \\
\hline $\mathrm{PVH}$ & - & ++ & - & ++ \\
\hline Sch & - & +++ & + & +++ \\
\hline $\mathrm{SOH}$ & - & ++ & - & + \\
\hline $\mathrm{VMH}$ & - & ++ & + & ++ \\
\hline $\mathrm{ZI}$ & - & $\mathrm{s} /+$ & - & $\mathrm{s}$ \\
\hline
\end{tabular}

$\mathrm{CB}-$ cell bodies $(+++$ : high density; ++ : moderate density; + : low density; - : no immunoreactivity). Nerve fibers $(+++$ : high density; ++ : moderate density; +: low density; s: single; -: no immunoreactivity). For nomenclature of the nuclei, see list of abbreviations in the description of Figure 2. fibers was visualized (Figs. 4d-g; 5b-d). The density observed for both neuropeptides ranged from single fibers to moderate (Table 1). Single immunoreactive fibers for SP and MET were found in $10(40 \%)$ and $14(56 \%)$ thalamic tracts/nuclei, respectively; a low density in $10(40 \%)$ and $6(24 \%)$ tracts/nuclei, and a moderate density in 5 nuclei (for both SP and MET, 20\%) (Table 1).

\section{Hypothalamus}

SP-Ir cell bodies were found in the lateral mammillary nucleus (Fig. 5f) and MET-Ir perikarya in the anterior hypothalamic area (Fig. 3e), lateral mammillary nucleus (Fig. 5e-g), lateral hypothalamic nucleus (Fig. 4c), posterior hypothalamic nucleus, suprachiasmatic nucleus and ventromedial hypothalamic nucleus (Fig. 2; Tables 1, 2).

Fibers containing SP (Figs. 3b, d, f; 4b) or MET (Figs. 3c, e, g; 4c) were observed in all hypothalamic tracts/nuclei studied, except for the optic tract and optic chiasm and hence these fibers showed a similar distribution (Table 1). Single SP-immunoreactive fibers were not observed, whereas single fibers containing MET were found in 3 hypothalamic nuclei $(18 \%)$. A low density of SP- and MET-Ir fibers were respectively visualized in $4(24 \%)$ and $2(12 \%)$ tract/ /nuclei; a moderate density in $6(35 \%)$ and $8(47 \%)$ hypothalamic nuclei, and a high density in $5(29 \%)$ and $2(12 \%)$ nuclei (Table 1$)$.

\section{Discussion}

\section{SP and MET immunoreactivity in the alpaca diencephalon}

For the first time, this study demonstrates the distribution of the MET- and SP-immunoreactive fibers and cell bodies in the alpaca diencephalon. In the hypothalamus the distribution of MET-Ir perikarya is more widespread than that observed for cell bodies containing SP. Our results have also shown a close neuroanatomical relationship between the enkephalinergic (MET) and tachykininergic (SP) systems in the alpaca diencephalon, suggesting that a functional relationship between both systems also occur. Currently, the mechanisms of possible intercellular communication between both systems are unknown and further studies are needed to explain them. However, this relationship could occur via volume transmission (paracrine) mechanisms and/or synaptic contacts $[25,26]$. Volume transmission is a slow mode of communication showing a high degree of divergence. In this mode of communication, peptides are released into the extracellular fluid and diffuse longer distances to reach high-affinity recep- 
a
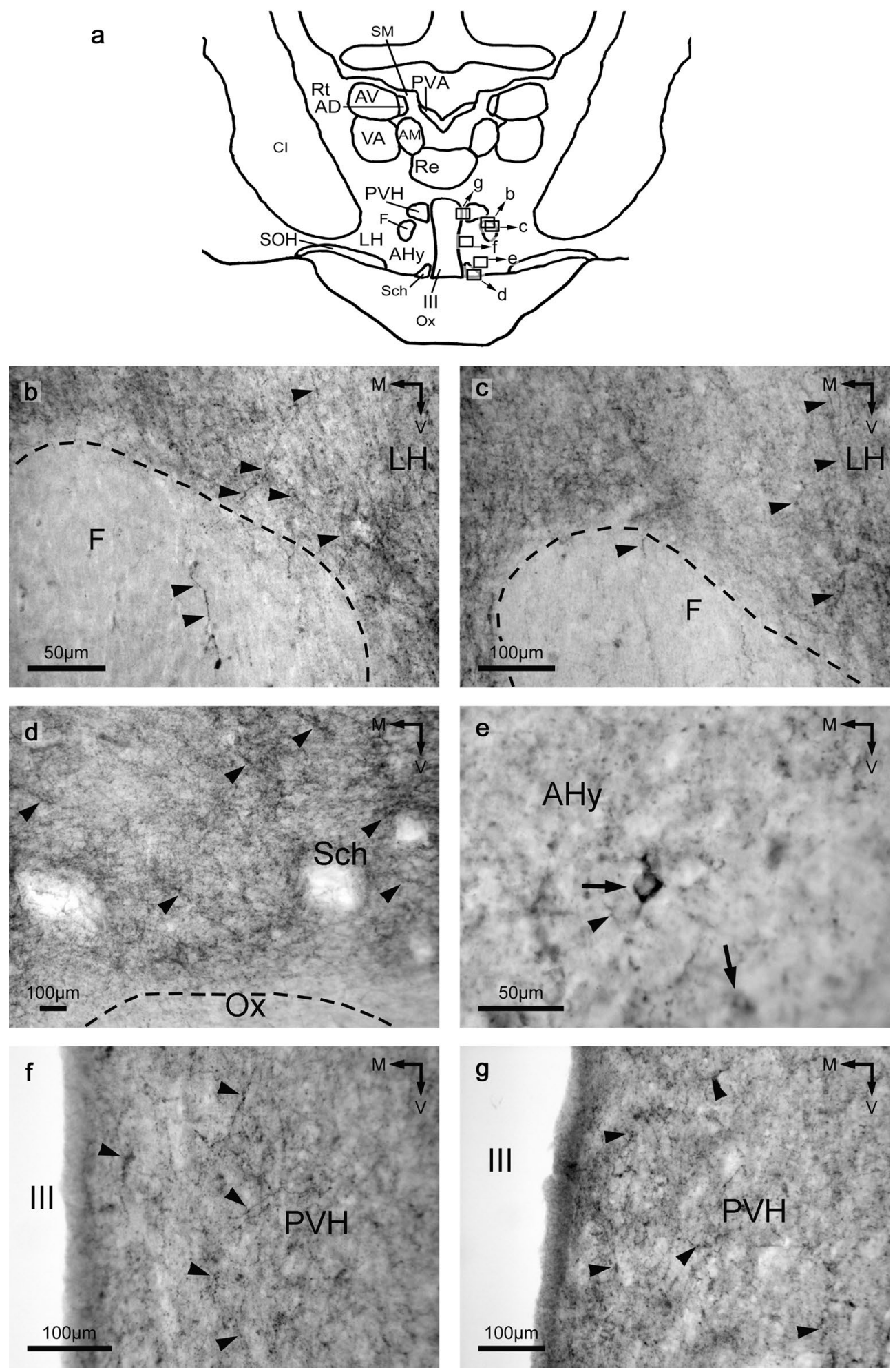

Figure 3. SP- and MET-immunoreactive cell bodies and fibers in the alpaca diencephalon. (a) Frontal section of the alpaca diencephalon. For the nomenclature of the nuclei, see Figure 2 (abbreviations). The photographs shown in $b-g$ were taken from the regions delimited by the rectangles in a (indicated as b, c, d, e, f and g). (b) SP-immunoreactive fibers (arrowheads) located in the lateral hypothalamic area (LH) and fornix (F). (c) MET-immunoreactive fibers (arrowheads) located in the lateral hypothalamic area (LH) and fornix (F). (d) SP-immunoreactive fibers (arrowheads) located in the suprachiasmatic nucleus (Sch). Ox - optic chiasm. (e) MET-immunoreactive perikarya (arrows) in the anterior hypothalamic area (AHy). (f) SP-immunoreactive fibers (arrowheads) in the paraventricular hypothalamic nucleus (PVH). III — third ventricle. (g) MET-immunoreactive fibers (arrowheads) in the paraventricular hypothalamic nucleus (PVH). M - medial. V - ventral. 

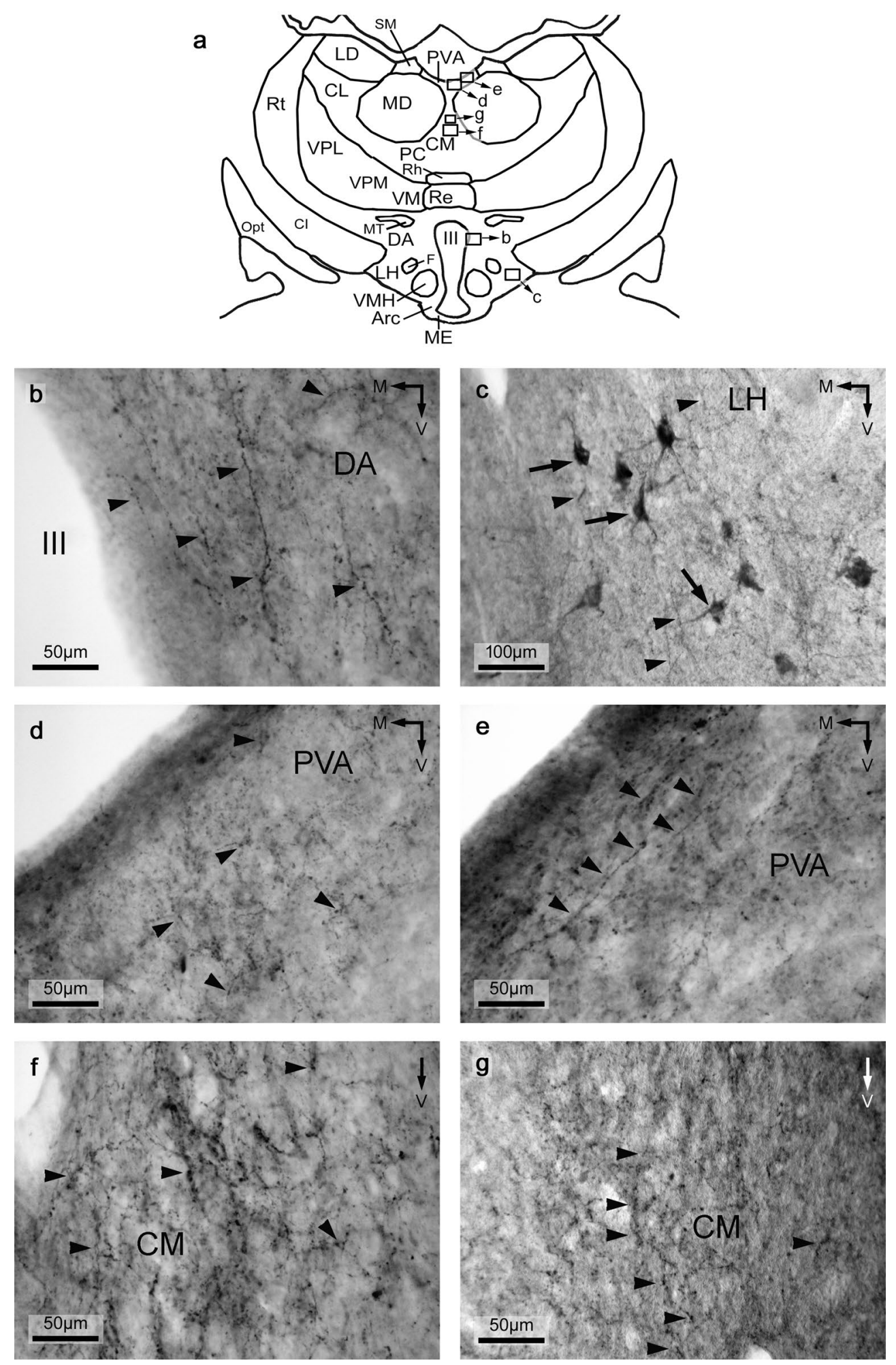

Figure 4. Immunoreactive fibers and cell bodies containing SP or MET in the alpaca diencephalon. (a) Frontal section of the alpaca diencephalon. For the nomenclature of the nuclei, see Figure 2 for abbreviations. The photographs shown in b-g were taken from the regions delimited by the rectangles in a (indicated as b, c, d, e, f and g). (b) SP-immunoreactive fibers (arrowheads) located in the dorsal hypothalamic area (DA). III - third ventricle. (c) MET-immunoreactive cell bodies (arrows) in the lateral hypothalamic area (LH). Arrowheads: immunoreactive fibers. (d) SP-immunoreactive fibers (arrowheads) located in the paraventricular thalamic nucleus (PVA). (e) MET-immunoreactive fibers (arrowheads) located in the paraventricular thalamic nucleus (PVA). (f) SP-immunoreactive fibers (arrowheads) in the central medial thalamic nucleus (CM). (g) MET-immunoreactive fibers (arrowheads) in the central medial thalamic nucleus (CM). M - medial. V - ventral. 
a
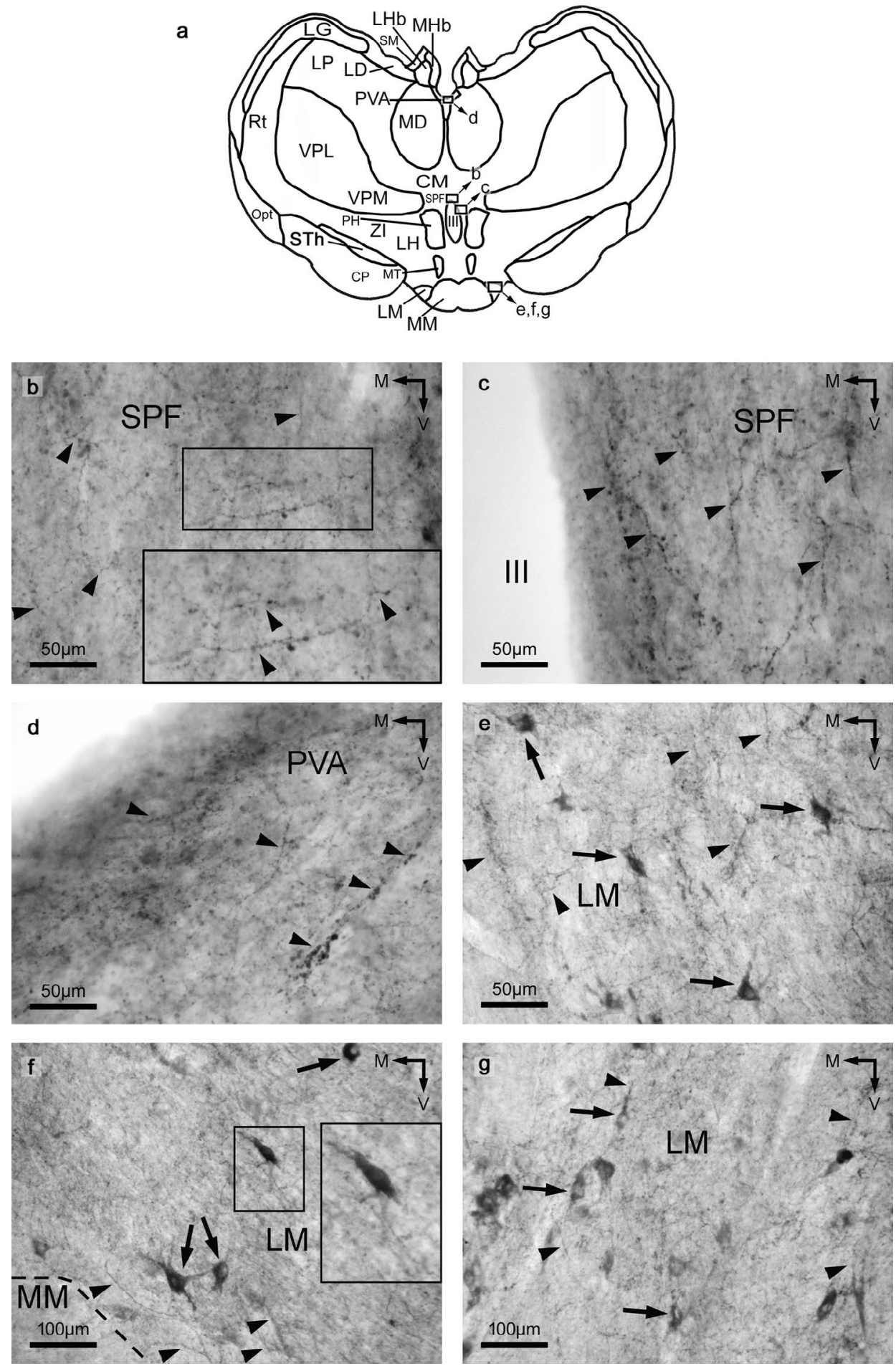

Figure 5. SP- and MET-immunoreactive fibers and cell bodies in the alpaca diencephalon. (a) Frontal section of the alpaca diencephalon. For the nomenclature of the nuclei, see Figure 2 (abbreviations). The photographs shown in $b-g$ were taken from the regions delimited by the rectangles in a (indicated as b, c, d, e, f and g). (b) SP-immunoreactive fibers (arrowheads) located in the subparafascicular thalamic nucleus (SPF). The region delimited by the small rectangle is showed at higher magnification. (c) MET-immunoreactive fibers (arrowheads) in the subparafascicular thalamic nucleus (SPF). III - third ventricle. (d) SP-immunoreactive fibers (arrowheads) located in the paraventricular thalamic nucleus (PVA). (e) MET-immunoreactive cell bodies (arrows) located in the lateral mammillary nucleus (LM). Arrowheads: immunoreactive fibers. (f) SP-immunoreactive cell bodies (arrows) in the lateral mammillary nucleus (LM). The region delimited by the small rectangle is showed at higher magnification. Arrowheads show immunoreactive fibers or dendrites. (g) MET-immunoreactive cell bodies (arrows) in the lateral mammillary nucleus (LM). Arrowheads show immunoreactive fibers or dendrites. $\mathrm{M}$ - medial. V - ventral. 
Table 2. Alpaca diencephalon: morphological characteristics of the MET- and SP-immunoreactive cell bodies

\begin{tabular}{|l|c|c|c|c|}
\hline Nucleus & Density & Size & Shape & Dendritic processes \\
\hline MET- immunoreactive cell bodies & & & & \\
\hline AHy & + & Medium & Polygonal & $2-3$ \\
\hline LH & +++ & Large & Polygonal & $2-4$ \\
\hline LM & ++ & Large & Polygonal & $2-4$ \\
\hline PHy & ++ & Large & Polygonal, oval & $2-3$ \\
\hline Sch & + & Large & Polygonal & $2-5$ \\
\hline VMH & + & Medium & Pyriform, oval & 1 \\
\hline SP- immunoreactive cell bodies & & & & \\
\hline LM & + & Large & Polygonal, oval & $2-4$ \\
\hline
\end{tabular}

+++ : high density; ++: moderate density; +: low density. For nomenclature of the nuclei, see list of abbreviations.

tors (e.g. neurokinin-1 and delta receptors) located in cell membranes [25, 27]. Moreover, both peptides could exert an autocrine action.

Our results show a neuroanatomical basis for future physiological investigations to study activities in which SP and MET are involved in the alpaca diencephalon. These actions are currently unknown, but the widespread distribution of SP- and MET-immunoreactive structures in the alpaca diencephalon suggests that both neuropeptides are involved in many physiological actions, in which SP and MET could interact. In mammals, it is known that SP regulates the release of prolactin, luteinizing hormone, dopamine and ACTH and that this undecapeptide is involved in vascular permeability, blood pressure and respiratory mechanisms, whereas MET has been involved in visual mechanisms, inhibition of the release of acetylcholine, dopamine, vasopressin and $\mathrm{SP}$ and controls the hypophysis [2]. For example, the presence of immunoreactive fibers containing SP or MET in the alpaca diencephalic nuclei involved in the transmission of pain signals suggests that SP is involved in this transmission and MET in the control of the pain transmission [28, 29]. Moreover, according to the neuroanatomical distribution of both peptides in the alpaca diencephalon and to the known actions in which the diencephalic nuclei are involved in other mammals, more physiological actions for SP/MET can be suggested in the camelid. Thus, in mammals, the lateral hypothalamic nucleus has been involved in feeding behavior, sleep and arousal, [30, 31]; the arcuate and paraventricular hypothalamic nuclei in neuroendocrine and stress mechanisms [32], and the suprachiasmatic nucleus in the circadian rhythm [33]. MET has been observed in the alpaca lateral hypothalamic nucleus and this suggests that in the camelid the peptide could be involved in the previous mentioned actions observed in other mammals. Moreover, it is known that the lateral mammillary nucleus is involved in the control of special localization of head and angular velocity [34]. The observation of cell bodies containing SP or MET in the latter nucleus suggests that in alpaca both peptides could be involved in this action.

\section{Neuropeptides in the alpaca diencephalon}

Using immunohistochemical techniques, the distribution of several neuropeptides in the alpaca diencephalon (somatostatin, CGRP, ACTH, $\alpha \mathrm{MSH}$, beta-endorphin, alpha-neo-endorphin, leucine-enkephalin, neurotensin) has been previously published $[10-12,14]$. Thus, in the alpaca diencephalon, the presence of peptidergic-immunoreactive fibers has been studied for ten neuropeptides (including SP and MET) [10-12,14]. In all cases, the distribution of the peptidergic-immunoreactive fibers containing the mentioned ten neuropeptides in the alpaca thalamus and hypothalamus was widespread and, in the same diencephalic nuclei (e.g. anterior hypothalamic area, arcuate nucleus, central medial thalamic nucleus, paraventricular thalamic nucleus, reuniens and rhomboid thalamic nuclei), the presence of all ten neuropeptides in fibers has been demonstrated. This means, in general, that: (i) a close neuroanatomical relationship occurs between the neuropeptides studied [10-12, 14], (ii) the peptidergic systems show the same/similar distribution, (iii) the coexistence of neuropeptides is possible, and (iv) in most of the alpaca diencephalic nuclei, an elaborate modulation of the functions of many neuropeptides occurs. It is important to note that the distribution of immunoreactive fibers containing SP, MET, somatostatin, CGRP, beta-endorphin, $\alpha \mathrm{MSH}$, alpha-neo-endorphin or neurotensin was similar and that the distribution of fibers containing 
ACTH or leucine-enkephalin, although widespread, was lesser than the previous eight neuropeptides $[10-12,14]$. Regarding the peptidergic cell bodies found in the alpaca diencephalon, these perikarya were only observed in the hypothalamus [10-12, 14]. No immunoreactive cell body for ACTH was found in the hypothalamus, whereas the other neuropeptides showed a very restricted distribution: beta-endorphin and SP were observed in 1 nucleus; leucine-enkephalin in 2 nuclei; somatostatin in 3 nuclei; $\alpha \mathrm{MSH}$ in 5 nuclei and MET, CGRP, alpha-neo-endorphin and neurotensin in 6 nuclei $[10-12,14]$. In the lateral and ventromedial hypothalamic nuclei, the presence of six neuropeptides (CGRP, somatostatin, $\alpha \mathrm{MSH}$, alpha-neo-endorphin, neurotensin and MET) has been reported in perikarya; four neuropeptides (CGRP, $\alpha \mathrm{MSH}$, neurotensin and MET) in cell bodies located in the anterior hypothalamic area and arcuate nucleus; three neuropeptides (CGRP, alpha-neo-endorphin and neurotensin) in the dorsal hypothalamic area and paraventricular and supraoptic hypothalamic nuclei and two of them in the lateral mammillary nucleus, posterior hypothalamic nucleus and suprachiasmatic nucleus. The possible coexistence of these neuropeptides in the hypothalamic cell bodies must be studied in the future. Finally, it is important to remark that in this and the previous studies performed in the alpaca, for ethical considerations no colchicine was administered to animals $[10-12,14]$. This could explain the restricted distribution of the peptidergic perikarya in the alpaca diencephalon, since it is known that in general the administration of colchicine increases the number and distribution of the peptidergic cell bodies.

\section{SP and MET in the mammalian diencephalon}

Many immunohistochemical studies regarding the distribution of SP and MET in the mammalian diencephalon have been performed [15, 16, 22, 35-45]. In general, the widespread distribution of the MET-immunoreactive fibers found in the alpaca diencephalon is quite similar to the distribution reported in other mammals. However, some differences occur. For example, in the cat/dog thalamus, MET-immunoreactive fibers were mainly observed in the midline nuclei $[16$, 22], whereas in alpaca these fibers were also observed in the lateral thalamic nuclei. In the hypothalamus, the dog and alpaca showed the same distribution and this was a slight more widespread than that found in the cat hypothalamus $[17,22]$. By contrast, many differences can be observed when comparing the distribution of the MET-immunoreactive perikarya in the mammalian diencephalon. These differences are due to the methodology applied (administration of colchicine; as indicated above, this drug is used to increase the number of peptidergic cell bodies). In general, in animals treated with colchicine a widespread distribution of immunoreactive cell bodies was observed [17, 22, 37, 38]. For example, in rats, cats and dogs treated with the drug, a widespread distribution of cell bodies containing MET was observed in the thalamus and hypothalamus [17, 22, 37, 38]. However, this widespread distribution was not observed here in the diencephalon of alpacas because they were not treated with colchicine. In summary, in comparison with other mammals, the distribution of MET-immunoreactive cell bodies in the alpaca diencephalon is very restricted.

In general, the distribution of the SP-immunoreactive fibers observed in the diencephalon of the alpaca is similar to that reported in other mammalian species (e.g. rat, human) $[15,36,43]$. Thus, in the hypothalamus of the three species a widespread distribution of SP-immunoreactive fibers was observed, whereas in the rat and human thalamus these fibers were mainly located in the midline nuclei but in the alpaca fibers containing SP were observed in both midline and lateral thalamic nuclei $[15,36,43]$. Regarding the distribution of the SP-immunoreactive perikarya in the mammalian diencephalon, a more widespread distribution (in both thalamus and hypothalamus) was observed in rats than in alpacas and humans [36, 43]. This was due to the administration of colchicine to rats. In both alpacas and humans, SP-immunoreactive cell bodies showed a very restricted distribution in the diencephalon.

In summary, this study increases the knowledge on the neuroanatomical distribution of the tachykininergic (SP) and enkephalinergic (MET) peptidergic systems in the alpaca diencephalon. SP- and MET-immunoreactive fibers showed a widespread and similar distribution in the diencephalon. A close neuroanatomical relationship between SP- and MET-immunoreactive fibers was found, suggestive of multiple physiological interactions between both neuropeptides. The distribution of the cell bodies containing SP is very restricted, whereas MET-immunoreactive perikarya show a moderately widespread distribution in the hypothalamus.

\section{Acknowledgements}

The authors wish to thank Professor Gérard Tramu (Université de Bordeaux I, France) for the gift of primary antibodies and the Language Service of the Universidad de Salamanca (Spain) for supervising the English text. This work has been supported by "Programa XI: Financiación de Unidades de Excelencia de la Universidad de Salamanca" (Spain). 


\section{References}

1. Bux F, Bhagwandin A, Fuxe K, et al. Organization of cholinergic, putative catecholaminergic and serotonergic nuclei in the diencephalon, midbrain and pons of sub-adult male giraffes. J Chem Neuroanat. 2010; 39(3): 189-203, doi: 10.1016/j. jchemneu.2009.09.006, indexed in Pubmed: 19808092.

2. Coveñas R, Mangas A, Narváez JA. Introduction to neuropeptides. In: Coveñas R, Mangas A, Narváez JA, eds. Focus on Neuropeptide Research. Trivandrum: Transworld Research Network; 2007: 1-26.

3. Ebner K, Singewald N. The role of substance $P$ in stress and anxiety responses. Amino Acids. 2006; 31(3): 251-272, doi: 10.1007/s00726-006-0335-9, indexed in Pubmed: 16820980.

4. Ebner K, Muigg P, Singewald G, et al. Substance P in stress and anxiety: NK-1 receptor antagonism interacts with key brain areas of the stress circuitry. Ann N Y Acad Sci. 2008; 1144: 61-73, doi: 10.1196/annals.1418.018, indexed in $\mathrm{Pu}-$ bmed: 19076365 .

5. Graefe S, Mohiuddin SS. Biochemistry, substance P. Treasure Island (FL): StatPearls Publishing; 2020. PMID: 32119470.

6. Hertler B, Hosp JA, Blanco MB, et al. Substance P signalling in primary motor cortex facilitates motor learning in rats. PLoS One. 2017; 12(12): e0189812, doi: 10.1371/journal. pone.0189812, indexed in Pubmed: 29281692.

7. Mashaghi A, Marmalidou A, Tehrani M, et al. Neuropeptide substance $\mathrm{P}$ and the immune response. Cell Mol Life Sci. 2016; 73(22): 4249-4264, doi: 10.1007/s00018-016-2293-z, indexed in Pubmed: 27314883.

8. Ribeiro-da-Silva A, Hökfelt T. Neuroanatomical localisation of substance $\mathrm{P}$ in the CNS and sensory neurons. Neuropeptides. 2000; 34(5): 256-271, doi: 10.1054/npep.2000.0834, indexed in Pubmed: 11049730.

9. Ebrahimi S, Javid H, Alaei A, et al. New insight into the role of substance $\mathrm{P} /$ neurokinin-1 receptor system in breast cancer progression and its crosstalk with microRNAs. Clin Genet. 2020 [Epub ahead of print], doi: 10.1111/cge.13750, indexed in Pubmed: 32266968.

10. Coveñas R, Mangas A, Medina LE, et al. Mapping of somatostatin-28 (1-12) in the alpaca diencephalon. J Chem Neuroanat. 2011; 42(1): 89-98, doi: 10.1016/j.jchemneu.2011.06.006, indexed in Pubmed: 21729751.

11. Coveñas R, Sánchez ML, Mangas A, et al. Mapping of CGRP in the alpaca diencephalon. J Chem Neuroanat. 2012; 45(1-2): 36-44, doi: 10.1016/j.jchemneu.2012.07.004, indexed in $\mathrm{Pu}-$ bmed: 22922318.

12. Manso B, Sánchez ML, Medina LE, et al. Immunohistochemical mapping of pro-opiomelanocortin- and pro-dynorphin-derived peptides in the alpaca (Lama pacos) diencephalon. J Chem Neuroanat. 2014; 59-60: 36-50, doi: 10.1016/j. jchemneu.2014.06.001, indexed in Pubmed: 24956196.

13. Marcos P, Arroyo-Jiménez MM, Lozano G, et al. Mapping of tyrosine hydroxylase in the diencephalon of alpaca (Lama pacos) and co-distribution with somatostatin-28 (112). J Chem Neuroanat. 2013; 50-51: 66-74, doi: 10.1016/j. jchemneu.2013.02.006, indexed in Pubmed: 23474224.

14. Sánchez ML, Mangas A, Medina LE, et al. Immunohistochemical mapping of neurotensin in the alpaca diencephalon. Folia Histochem Cytobiol. 2018; 56(1): 49-58, doi: 10.5603/ FHC.a2018.0003, indexed in Pubmed: 29516445.

15. Palkovits M. Neuropeptides in the brain. In: Ganong WF, Martini L, eds. Frontiers in Neuroendocrinology. New York: Raven Press. ; 1988: 1-44.

16. Conrath M, Covenas R, Romo R, et al. Distribution of Met-enkephalin immunoreactive fibres in the thalamus of the cat. Neurosci Lett. 1986; 65(3): 299-303, doi: 10.1016/03043940(86)90278-8, indexed in Pubmed: 3520398.
17. Coveñas R, Burgos C, Conrath M. Immunocytochemical study of met-enkephalin-like cell bodies in the cat hypothalamus. Neurosci Res. 1988; 5(4): 353-360, doi: 10.1016/01680102(88)90037-5, indexed in Pubmed: 3374865.

18. Burgos C, Aguirre JA, Alonso JR, et al. Immunocytochemical study of substance P-like fibres and cell bodies in the cat diencephalon. J Hirnforsch. 1988; 29(6): 651-657, indexed in Pubmed: 2466889.

19. Duque-Díaz E, Díaz-Cabiale Z, Narváez JA, et al. Mapping of enkephalins and adrenocorticotropic hormone in the squirrel monkey brainstem. Anat Sci Int. 2017; 92(2): 275-292, doi: 10.1007/s12565-016-0333-2, indexed in Pubmed: 26897373.

20. Duque-Díaz E, Coveñas R. Distribution of somatostatin-28 (1-12), calcitonin gene-related peptide, and substance $\mathrm{P}$ in the squirrel monkey brainstem: an immunocytochemical study. Anat Sci Int. 2019; 94(1): 86-100, doi: 10.1007/s12565-0180453-y, indexed in Pubmed: 30051271.

21. Mangas A, Yajeya J, Gonzalez N, et al. Detection of pantothenic acid-immunoreactive neurons in the rat lateral septal nucleus by a newly developed antibody. Folia Histochem Cytobiol. 2016; 54(4): 186-192, doi: 10.5603/FHC.a2016.0024, indexed in Pubmed: 27966211.

22. Pesini P, Pego-Reigosa R, Tramu G, et al. Distribution of met-enkephalin immunoreactivity in the diencephalon and the brainstem of the dog. J Chem Neuroanat. 2000; 19(4): 243-258, doi: 10.1016/s0891-0618(00)00071-5, indexed in Pubmed: 11036241.

23. Samsam M, Coveñas R, Csillik B, et al. Depletion of substance P, neurokinin $\mathrm{A}$ and calcitonin gene-related peptide from the contralateral and ipsilateral caudal trigeminal nucleus following unilateral electrical stimulation of the trigeminal ganglion; a possible neurophysiological and neuroanatomical link to generalized head pain. J Chem Neuroanat. 2001; 21(2): 161-169, doi: 10.1016/s0891-0618(01)00088-6, indexed in Pubmed: 11312057.

24. Sánchez ML, Vecino E, Coveñas R. Distribution of methionine-enkephalin in the minipig brainstem. J Chem Neuroanat. 2013; 50-51: 1-10, doi: 10.1016/j.jchemneu.2013.03.002, indexed in Pubmed: 23538385.

25. Fuxe K, Agnati LF, Coveñas R, et al. Volume transmission in transmitter peptide costoring neurons in the medulla oblongata. In: Barraco IRA, ed. Nucleus of the Solitary Tract. Boca Raton: CRC Press. ; 1994: 74-89, doi: 10.1201/9780429277214.

26. Fuxe K, Borroto-Escuela DO. Volume transmission and receptor-receptor interactions in heteroreceptor complexes: understanding the role of new concepts for brain communication. Neural Regen Res. 2016; 11(8): 1220-1223, doi: 10.4103/1673-5374.189168, indexed in Pubmed: 27651759.

27. Nusbaum M, Blitz D, Marder E. Functional consequences of neuropeptide and small-molecule co-transmission. Nat Rev Neurosci. 2017; 18(7): 389-403, doi: 10.1038/nrn. 2017.56.

28. Ralston HJ. Pain and the primate thalamus. Prog Brain Res. 2005; 149: 1-10, doi: 10.1016/S0079-6123(05)49001-9, indexed in Pubmed: 16226572.

29. Li JN, Sun Yi, Ji SL, et al. Collateral projections from the medullary dorsal horn to the ventral posteromedial thalamic nucleus and the parafascicular thalamic nucleus in the rat. Neuroscience. 2019; 410: 293-304, doi: 10.1016/j.neuroscience.2019.04.050, indexed in Pubmed: 31075313.

30. Urstadt KR, Berridge KC. Optogenetic mapping of feeding and self-stimulation within the lateral hypothalamus of the rat. PLoS One. 2020; 15(1): e0224301, doi: 10.1371/journal. pone.0224301, indexed in Pubmed: 31986148.

31. Szymusiak R, McGinty D. Hypothalamic regulation of sleep and arousal. Ann N Y Acad Sci. 2008; 1129: 275-286, doi: 10.1196/annals.1417.027, indexed in Pubmed: 18591488 . 
32. Coveñas R, de León M, Cintra A, et al. Coexistence of c-Fos and glucocorticoid receptor immunoreactivities in the CRF immunoreactive neurons of the paraventricular hypothalamic nucleus of the rat after acute immobilization stress. Neurosci Lett. 1993; 149(2): 149-152, doi: 10.1016/0304-3940(93)90758-d, indexed in Pubmed: 8474689.

33. Koinuma S, Asakawa T, Nagano M, et al. Regional circadian period difference in the suprachiasmatic nucleus of the mammalian circadian center. Eur J Neurosci. 2013; 38(6): 28322841, doi: 10.1111/ejn.12308, indexed in Pubmed: 23869693.

34. Blair HT, Cho J, Sharp PE. Role of the lateral mammillary nucleus in the rat head direction circuit: a combined single unit recording and lesion study. Neuron. 1998; 21(6): 1387-1397, doi: 10.1016/s0896-6273(00)80657-1, indexed in Pubmed: 9883731.

35. Bouras C, Taban CH, Constantinidis J. Mapping of enkephalins in human brain. An immunohistofluorescence study on brains from patients with senile and presenile dementia. Neuroscience. 1984; 12(1): 179-190, doi: 10.1016/03064522(84)90146-5, indexed in Pubmed: 6379499.

36. Bouras C, Vallet PG, Dobrinov H, et al. Substance P neuronal cell bodies in the human brain: complete mapping by immunohistofluorescence. Neurosci Lett. 1986; 69(1): 31-36, doi: 10.1016/0304-3940(86)90409-x, indexed in Pubmed: 2427977.

37. Covenas R, Romo R, Cheramy A, et al. Immunocytochemical study of enkephalin-like cell bodies in the thalamus of the cat. Brain Res. 1986; 377(2): 355-361, doi: 10.1016/00068993(86)90881-4, indexed in Pubmed: 3524752.

38. Coveñas R, Alonso JR, Conrath M. Immunocytochemical study of enkephalin-like cell bodies in the thalamus of the rat. Brain Res Bull. 1989; 23(4-5): 277-281, doi: 10.1016/03619230(89)90209-8, indexed in Pubmed: 2590840.
39. Finley JC, Maderdrut JL, Petrusz P. The immunocytochemical localization of enkephalin in the central nervous system of the rat. J Comp Neurol. 1981; 198(4): 541-565, doi: 10.1002/ cne.901980402, indexed in Pubmed: 7019273.

40. Haber SN, Wolfe DP, Groenewegen HJ, et al. The distribution of enkephalin immunoreactive fibers and terminals in the monkey central nervous system: an immunohistochemical study. Neuroscience. 1982; 7(5): 1049-1095, doi: 10.1016/0306-4522(82)91118-6, indexed in Pubmed: 7050764.

41. Hökfelt T, Elde R, Johansson O, et al. The distribution of enkephalin-immunoreactive cell bodies in the rat central nervous system. Neurosci Lett. 1977; 5(1-2): 25-31, doi: 10.1016/03043940(77)90160-4, indexed in Pubmed: 19604966.

42. Inagaki S, Parent A. Distribution of enkephalin-immunoreactive neurons in the forebrain and upper brainstem of the squirrel monkey. Brain Res. 1985; 359(1-2): 267-280, doi: 10.1016/0006-8993(85)91437-4, indexed in Pubmed: 3907752.

43. Ljungdahl A, Hökfelt T, Nilsson G. Distribution of substance P-like immunoreactivity in the central nervous system of the rat-I. Cell bodies and nerve terminals. Neuroscience. 1978; 3(10): 861-943, doi: 10.1016/0306-4522(78)90116-1, indexed in Pubmed: 366451.

44. Merchenthaler I, Maderdrut JL, Altschuler RA, et al. Immunocytochemical localization of proenkephalin-derived peptides in the central nervous system of the rat. Neuroscience. 1986; 17(2): 325-348, doi: 10.1016/0306-4522(86)90250-2, indexed in Pubmed: 3517687.

45. Sar M, Stumpf WE, Miller RJ, et al. Immunohistochemical localization of enkephalin in rat brain and spinal cord. J Comp Neurol. 1978; 182(1): 17-37, doi: 10.1002/cne.901820103, indexed in Pubmed: 359601.

Submitted: 10 January, 2020 Accepted after reviews: 29 April, 2020 Available as AoP: 2 June, 2020 